\title{
Influence of different oral rehydration solutions on abomasal conditions and the acid-base status of suckling calves
}

\author{
L. Bachmann, ${ }^{11}$ T. Homeier,† S. Arlt, $\ddagger$ M. Brueckner,§ H. Rawel,\# C. Deiner, ${ }^{*}$ and H. Hartmann* \\ *Department of Veterinary Physiology, Freie Universitaet Berlin, 14163 Berlin, Germany \\ †Institute of Microbiology and Epizootics, Freie Universitaet Berlin, 10115 Berlin, Germany \\ †Department of Animal Reproduction, Freie Universitaet Berlin, 14163 Berlin, Germany \\ §Institute of Food Technology and Food Chemistry, Technische Universitaet Berlin, 14195 Berlin, Germany \\ \#Institute of Nutrition Science, Universitaet Potsdam, 14558 Nuthetal OT Bergholz-Rehbruecke, Germany
}

\begin{abstract}
The aim of the study was to investigate the influence of oral rehydration solutions (ORS) on milk clotting, abomasal $\mathrm{pH}$, electrolyte concentrations, and osmolality, as well as on the acid-base status in blood of suckling calves, as treatment with ORS is the most common therapy of diarrhea in calves to correct dehydration and metabolic acidosis. Oral rehydration solutions are suspected to inhibit abomasal clotting of milk; however, it is recommended to continue feeding cow's milk or milk replacer (MR) to diarrheic calves to prevent body weight losses. Three calves with abomasal cannulas were fed MR, MR-ORS mixtures, or water-ORS mixtures, respectively. Samples of abomasal fluid were taken before and after feeding at various time points, and $\mathrm{pH}$, electrolyte concentrations, and osmolality were measured. The interference of ORS with milk clotting was examined in vivo and in vitro. To evaluate the effects of ORS on systemic acid-base status, the Stewart variables strong ion difference ([SID]), acid total $\left(\left[\mathrm{A}_{\text {tot }}\right]\right)$, and partial pressure of $\mathrm{CO}_{2}\left(\mathrm{pCO}_{2}\right)$ were quantified in venous blood samples drawn before and after feeding. Calves reached higher abomasal $\mathrm{pH}$ values when fed with MR-ORS mixtures than when fed MR. Preprandial $\mathrm{pH}$ values were re-established after 4 to $6 \mathrm{~h}$. Oral rehydration solutions prepared in water increased the abomasal fluid $\mathrm{pH}$ only for 1 to 2 h. Oral rehydration solutions with high $\left[\mathrm{SID}_{3}\right]\left(\left[\mathrm{Na}^{+}\right]\right.$ $\left.+\left[\mathrm{K}^{+}\right]-\left[\mathrm{Cl}^{-}\right]\right)$values produced significantly higher abomasal $\mathrm{pH}$ values and area under the curve data of the $\mathrm{pH}$ time course. Caseinomacropeptide, an indicator of successful enzymatic milk clotting, could be identified in every sample of abomasal fluid after feeding MR-ORS mixtures. The MR-ORS mixtures with $\left[\mathrm{SID}_{3}\right]$ values $\geq 92 \mathrm{mmol} / \mathrm{L}$ increased serum $\left[\mathrm{SID}_{3}\right]$ but did not change venous blood $\mathrm{pH}$. Oral rehydration solutions do
\end{abstract}

Received June 26, 2008.

Accepted December 2, 2008.

${ }^{1}$ Corresponding author: fridamin@gmx.de not interfere with milk clotting in the abomasum and can, therefore, be administered with milk. In this study, MR-ORS mixtures with high $\left[\mathrm{SID}_{3}\right]$ values caused an increase of serum $\left[\mathrm{SID}_{3}\right]$ in healthy suckling calves and may be an effective treatment for metabolic acidosis in calves suffering from diarrhea.

Key words: calf, milk clotting, oral rehydration solution, strong ion difference

\section{INTRODUCTION}

Acidemia and metabolic acidosis are important disorders of acid-base status in diarrheic calves (Hartmann et al., 1997). Neonatal diarrhea is the most common cause of death of calves in their first weeks of life (USDA, 2007) and is accompanied by a decrease of blood $\mathrm{pH}$ (Lorenz et al., 2005). Mortality, deprivation of calves, and treatment costs of neonatal diarrhea cause high economic losses in the cattle industry (Weigler et al., 1990).

Treatment with oral rehydration solutions (ORS) is the most common therapy for diarrheic calves with a sufficient suckle reflex. It is a cheap and effective method for the correction of dehydration and metabolic acidosis (Nappert and Spennick, 2003). Because feeding low-energy ORS exclusively causes gross energy deficits, it is advisable to continue feeding milk to prevent BW losses (Heath et al., 1989; Garthwaite et al., 1994). However, ORS are also known to increase abomasal fluid $\mathrm{pH}$ (Constable et al., 2006), thereby possibly inhibiting abomasal clotting of milk.

Currently, the acid-base status of humans and animals is evaluated by the Henderson-Hasselbalch equation. However, because the Henderson-Hasselbalch approach can only be accurately applied to plasma at approximately normal conditions in body temperature, blood $\mathrm{pH}$, serum protein, and sodium concentration, its utility is minimized for describing disturbances of acid-base status in ruminants (Constable, 1999). In the 1980s, Peter Stewart generated the strong ion model of acid-base status, offering an invaluable novel 
insight into the pathophysiology of mixed acid-base disorders (Constable, 1999). According to this model, 3 independent variables of the acid-base status exist: 1) strong ion difference (SID) = strong cations minus strong anions; 2) acid total $\left(\mathbf{A}_{\text {tot }}\right)=$ total concentration of nonvolatile weak acids; and 3) partial pressure of carbon dioxide $\left(\mathbf{p C O}_{2} ;\right.$ Stewart, 1981). According to Stewart, SID, $\mathrm{A}_{\text {tot }}$, and $\mathrm{pCO}_{2}$ are the primary variables of acid-base status, and all other variables (e.g., $\mathrm{pH} /$ $\left.\left[\mathrm{H}^{+}\right],\left[\mathrm{HCO}_{3}^{-}\right]\right)$are secondary variables derived from the primary variables.

Sodium and chloride concentrations are the major components of [SID] (i.e., concentration of SID) as they are quantitatively the most important ions in the extracellular fluid (Constable, 1999). Other strong ions are potassium, magnesium, calcium, and sulfate; however, these ions have a less dominant role in adjusting the plasma $\mathrm{pH}$ because of their low plasma concentrations and smaller variability. In addition, lactate and other organic acids such as BHBA or acetoacetate behave like strong ions in plasma and are completely dissociated at physiological $\mathrm{pH}$. Furthermore, some plasma ions, especially anions such as sulfate, BHBA, or other organic acids, cannot be determined or are not detected routinely (Constable, 1997). Therefore, the determination of [SID] is an approximate calculation and is predominantly expressed as $\left[\mathbf{S I D}_{3}\right]=\left[\mathrm{Na}^{+}\right]+$ $\left[\mathrm{K}^{+}\right]-\left[\mathrm{Cl}^{-}\right](\mathrm{mmol} / \mathrm{L})$ or $\left[\mathbf{S I D}_{4}\right]=\left[\mathrm{Na}^{+}\right]+\left[\mathrm{K}^{+}\right]-$ $\left[\mathrm{Cl}^{-}\right]-\left[\right.$lactate $\left.{ }^{-}\right](\mathrm{mmol} / \mathrm{L})$ (Constable et al., 2005b). An increase of [SID] leads to alkalosis, and a decrease leads to acidosis (Constable, 1999).

In contrast to the buffer ion $\mathrm{HCO}_{3}{ }^{-}$(an open buffer system affected by $\mathrm{pCO}_{2}$ ), the elements of $\mathrm{A}_{\text {tot }}$ are nonvolatile. Acid total is particularly represented by albumin and phosphate, but bovine globulins have a net negative charge and thus are also considered to be a fraction of $A_{\text {tot }}$ (Constable, 2002). Determination of $\left[A_{t o t}\right]$ (i.e., concentration of $A_{t o t}$ ) in calf serum is possible by using the method of Constable et al. $(2005 \mathrm{~b})$ : $\left[\mathrm{A}_{\text {tot }}\right]$ $(\mathrm{mmol} / \mathrm{L})=0.343(\mathrm{mmol} / \mathrm{g}) \times[$ total protein $](\mathrm{g} / \mathrm{L})$ or $0.622(\mathrm{mmol} / \mathrm{g}) \times$ [albumin] $(\mathrm{g} / \mathrm{L})$.

Recent studies have shown that acidemia in diarrheic calves is due to strong ion acidosis $\left(\left[\mathrm{Na}^{+}\right] \downarrow,\left[\mathrm{Cl}^{-}\right] \uparrow\right.$, [lactate $\left.\left.^{-}\right] \uparrow\right)$ and nonvolatile buffer ion acidosis $\left(\left[\mathrm{A}_{\mathrm{tot}}\right] \uparrow\right)$ as a result of the dehydration [L. Bachmann, J. Berchtold (veterinary practice, Obing, Germany), C. SieglingVlitakis (Department of Veterinary Physiology, Freie Universitaet Berlin, Berlin, Germany), A. Willing and E. Radtke (Institute of Veterinary Diagnostics, Berlin, Germany), H. Hartmann; unpublished data; Constable et al., 2005b]. Furthermore, hyper-D-lactatemia frequently occurs in diarrheic calves and produces all the clinical signs attributed to metabolic acidosis (Lorenz et al., 2005). These findings imply that ORS should contain high values for SID; however, few studies have evaluated commercially available ORS on the basis of the Stewart variables (Staempfli et al., 1996).

The purpose of this study was to investigate the influence of ORS on abomasal electrolyte concentrations, $\mathrm{pH}$, and osmolality, as well as on milk clotting and the acid-base status of suckling calves according to the Stewart model.

\section{MATERIALS AND METHODS}

\section{Animals}

Three male calves (aged 11, 15, and $23 \mathrm{~d}$ ) obtained from local farms were surgically fitted with abomasal plastic cannulas as described previously (Reinhold et al., 2006) and kept in calf boxes with rubber mats and straw bedding. Experiments were approved by federal authorities for animal research (LAGeSo, Berlin, Germany) and conducted in accordance with the principles and specific guidelines presented in the Guide for the Care and Use of Agricultural Animals in Agricultural Research and Teaching (FASS, 1999). Before the start of experiments and between 2 experimental phases, calves were fed 4 times a day $(0800,1400,1900$, and $2230 \mathrm{~h})$, with high-quality, all-milk-protein milk replacer (MR, $50.5 \%$ skimmed milk powder; $30 \%$ sweet whey powder; $15.5 \%$ vegetable oil, refined; $3 \%$ wheat starch; $2 \%$ additives).

\section{Experimental Design}

Experiments started $3 \mathrm{~d}$ after cannulation (calves at 14, 18, and $26 \mathrm{~d}$; BW: $60-70 \mathrm{~kg}$ ); the experimental period consisted of $5 \mathrm{~d}$ of experimental feeding, then $2 \mathrm{~d}$ for recovery, and then another $5 \mathrm{~d}$ of experimental feeding. Four ORS with different buffer ions were used: acetate (ORS-1; Bayer AG, Leverkusen, Germany), propionate (ORS-2, Chevita, Pfaffenhofen, Germany), bicarbonate (ORS-3, Albrecht, Aulendorf, Germany), and citrate (ORS-4, Pfizer, New York, NY) (Table 1). Depending on the preparation in water or MR and the amount of ORS used, different values for $\mathrm{pH}$, osmolality, and $\left[\mathrm{SID}_{3}\right]$ were measured or calculated for the mixtures (Table 2). During the experimental phases, calves received $2 \mathrm{~L}$ of MR, MR-ORS mixture (ORS-1A, ORS-1C, ORS-2A, ORS-3A, or ORS-4A), or waterORS mixture (ORS-1B, ORS-2B, ORS-3B, or ORS-4B) at 0800 and $1400 \mathrm{~h}$ and were deprived of water and hay. Abomasal fluid samples were collected immediately before feeding and 30,60, 120, and 240 min after feeding. Blood samples were taken by jugular vein puncture immediately before feeding, and 120 and $240 \mathrm{~min}$ after feeding. In the evenings (at 1900 and $2230 \mathrm{~h}$ ), calves 
Table 1. Ingredients of oral rehydration solutions (ORS)

\begin{tabular}{|c|c|c|c|c|c|c|}
\hline ORS & \multicolumn{3}{|c|}{ Ions $(\mathrm{mmol} / \mathrm{L})$} & Anion/ buffer & Recommended application & Further ingredients \\
\hline ORS- $1^{1}$ & 101 & 22 & 49 & Acetate & In milk/milk replacer or water & Glucose \\
\hline ORS- $3^{3}$ & 81 & 13 & 45 & Bicarbonate & In water & Lactose, glycine, $\mathrm{Ca}^{2+}, \mathrm{Mg}^{2+}$ \\
\hline
\end{tabular}

${ }^{1}$ Glutellac (Bayer AG, Leverkusen, Germany).

${ }^{2}$ Boviferm (Chevita GmbH, Pfaffenhofen, Germany).

${ }^{3}$ Lytafit (Albrecht GmbH, Aulendorf, Germany).

${ }^{4}$ Lectade Plus (Pfizer Inc. Animal Health Group, New York, NY).

received only MR (total amount of fluid ration per day according to $12 \%$ of $\mathrm{BW}$ ) and had free water and hay access. The feeding regimens were randomly assigned; MR and the different ORS mixtures were fed at least 5 times through the whole test period. At the end of the study, calves were killed with an overdose of sodium pentobarbital (Eutha 77, $2 \mathrm{~mL} / 10 \mathrm{~kg}$, Essex Pharma, Munich, Germany).

\section{Measurements and Analyses}

In total, 58 feeding times were analyzed. Directly after abomasal fluid sampling, $\mathrm{pH}$ was measured with a $\mathrm{pH}$ electrode (Mettler Toledo, Giessen, Germany). Samples were then frozen $\left(-20^{\circ} \mathrm{C}\right)$ until measurement of osmolality (Osmomat 030-D, Gonotec, Berlin, Germany; freezing point depression), or $\left[\mathrm{Na}^{+}\right],\left[\mathrm{K}^{+}\right]$, and $\left[\mathrm{Cl}^{-}\right]$ (Modular SWA Hitachi, Roche Diagnostics, Hvidovre, Denmark; ion selective electrode), respectively. Based on the concentrations of these electrolytes, $\left[\mathrm{SID}_{3}\right]$ was calculated. Area under curve (AUC) of the pH-time curve was calculated by the software SigmaPlot (version 8.0, Systat Software, Erkrath, Germany). Osmolality and $\mathrm{pH}$ measurements of the various mixtures were performed accordingly, and $\left[\mathrm{SID}_{3}\right]$ for $\mathrm{MR}$ and ORS were calculated using the manufacturer's data on electrolyte concentrations in the products.

The acid-base status in blood was estimated by the parameters of Stewart. Therefore, serum concentrations of $\mathrm{Na}^{+}, \mathrm{K}^{+}, \mathrm{Cl}^{-}$(ion selective electrode), protein, phosphate (Modular, Roche Diagnostics, photometry), and albumin (CAPILLARYS, Sebia Inc., Norcross GA; capillary electrophoresis), as well as $\mathrm{pCO}_{2}$ and $\mathrm{pH}$ (ABL 5, Radiometer, Copenhagen, Denmark; blood gas analysis) were determined.

Calculated change in plasma volume 120 and 240 min after feeding was assessed from the serum protein concentration before feeding $\left(\mathrm{P}_{0}\right)$ and the serum protein concentration 120 and 240 min after feeding $\left(\mathrm{P}_{120}, \mathrm{P}_{240}\right):\left(\mathrm{P}_{0}-\mathrm{P}_{120 / 240}\right) \times 100 / \mathrm{P}_{120 / 240}$ (Nouri and Constable, 2006).

\section{Milk Clotting}

In vitro milk clotting was quantified after addition of chymosin (Chy-Max Plus, Chr. Hansen A/S, Horshølm, Denmark; EC 3.4.23.4; $50 \mu \mathrm{L} / 100 \mathrm{~mL}$ ) to fresh cow's milk, MR, or the MR-ORS mixtures at original $\mathrm{pH}$ by measuring dynamic viscosity for $60 \mathrm{~min}$ using a viscosimeter (Physica-Rheoswing, Physica Messtechnik,

Table 2. Composition of feeding formulations concerning strong ion difference $\left(\left[\mathrm{SID}_{3}\right]=\left[\mathrm{Na}^{+}\right]+\left[\mathrm{K}^{+}\right]-\left[\mathrm{Cl}^{-}\right]\right)$, $\mathrm{pH}$, and osmolality

\begin{tabular}{|c|c|c|c|c|c|}
\hline Formulation $^{1}$ & ORS & Prepared in & {$\left[\mathrm{SID}_{3}\right](\mathrm{mmol} / \mathrm{L})$} & $\mathrm{pH}( \pm \mathrm{SD})$ & Osmolality $(\mathrm{mOsm} / \mathrm{kg})$ \\
\hline ORS-1A & ORS-1 & MR & 115 & $6.1 \pm 0.06$ & 602 \\
\hline ORS-1B & ORS-1 & Water & 74 & $6.0 \pm 0.03$ & 298 \\
\hline ORS-2A & ORS-2 & MR & 119 & $6.1 \pm 0.05$ & 823 \\
\hline ORS-2B & ORS-2 & Water & 77 & $6.3 \pm 0.03$ & 501 \\
\hline ORS-3A & ORS-3 & MR & 92 & $6.9 \pm 0.09$ & 665 \\
\hline ORS-4B & ORS-4 & Water & 31 & $6.2 \pm 0.02$ & 299 \\
\hline
\end{tabular}

${ }^{1} \mathrm{MR}=$ milk replacer (Kälbermilch UNI, Raiffeisen GmbH, Muenster, Germany); ORS = oral rehydration solutions. 
Stuttgart, Germany). In a second trial, the conditions occurring naturally in the abomasum were simulated by acidifying the samples with hydrochloric acid to $\mathrm{pH} \sim 5.5$ and then adding chymosin; again, dynamic viscosity was measured for $60 \mathrm{~min}$. To determine the precipitation of the caseins caused by acidification, static viscosity was measured before and after adding hydrochloric acid to a $\mathrm{pH}$ of 4.7 .

In vivo, the existence of 2 phases in the abomasal fluid samples - the curd and the whey-indicated that milk clotting had occurred in the abomasum. As an indicator for the successful proteolytic activity of chymosin (Brückner and Senge, 2007), caseinomacropeptide (CMP) concentration was measured in abomasal fluid by using an HPLC method described by Minikiewicz et al. (1996) and calculating AUC of the CMP peaks.

\section{Statistical Analyses}

Data were expressed as arithmetic mean $( \pm$ standard deviation) and analyzed by using repeated-measures ANOVA (GLM-repeated). For the parameters that offered statistically significant effects of time and feeding regimen or statistically significant coherencies between time and feeding regimen, respectively, dependent $t$-tests between the individual time points or feeding regimens were computed. Pearson product-moment correlation coefficients were calculated between the $\mathrm{pH}$ or $\left[\mathrm{SID}_{3}\right]$ of the ORS and the AUC of the pH-time curve and between the $\left[\mathrm{SID}_{3}\right]$ of abomasal fluid and the abomasal $\mathrm{pH}$, respectively. For statistical analysis, the software SPSS (version 16.0, SPSS Inc., Chicago, IL) was used and a value of $P<0.05$ was considered to be statistically significant.

\section{RESULTS}

\section{Animals}

The abomasal cannulation was well tolerated by all calves with maintenance of appetite, normal calf growth, and no episodes of pyrexia. Feeding of MR and ORS in combination did not cause any symptoms of diarrhea such as loose bowels or increased defecation frequency.

\section{Abomasal $\mathrm{pH}$ and $\mathrm{pH}$-Time Course}

After feeding of $\mathrm{MR}$, the abomasal $\mathrm{pH}$ reached values of $5.19 \pm 0.67$ ( $\mathrm{AUC}=937 \pm 200)$ and then continuously decreased. Four hours after feeding of MR, the preprandial values were re-established. Calves reached higher abomasal $\mathrm{pH}$ values when fed with MR-ORS mixtures compared with feeding MR only (Figure 1A).
The preprandial values of abomasal $\mathrm{pH}$ were obtained 5.5 to $6 \mathrm{~h}$ after feeding of MR-ORS mixtures. Remarkably, the $\mathrm{pH}$ of the test meals did not correlate with the AUC of the pH-time curve [Pearson product-moment correlation coefficient $\left.\left(\mathbf{r}_{\mathrm{s}}\right)=-0.207, P>0.05\right)$, but significant correlations were observed between the AUC and the $\left[\mathrm{SID}_{3}\right]$ values of the different feeding regimens $\left(\mathrm{r}_{\mathrm{s}}=0.674, P<0.01\right)$. For example, after feeding ORS$1 \mathrm{~A}\left(\mathrm{pH}=6.1, \mathrm{SID}_{3}=115 \mathrm{mmol} / \mathrm{L}\right)$, the $\mathrm{pH}$ increase was more pronounced than after administration of MR, although the $\mathrm{pH}$ of the $\mathrm{MR}$ was slightly higher $(\mathrm{pH}$ $=6.3, \mathrm{SID}_{3}=42 \mathrm{mmol} / \mathrm{L}$ ). The abomasal $\mathrm{pH}$ also correlated with the $\left[\mathrm{SID}_{3}\right]$ values in abomasal ingesta (Figure 2).

After feeding the water-ORS mixtures, the total performance of abomasal $\mathrm{pH}$ was not as pronounced as after feeding of MR or MR-ORS mixtures (Figure 1B), and with the exception of ORS-2B, the AUC of the $\mathrm{pH}-$ time curve also differed significantly from those after feeding the same ORS prepared in $\mathrm{MR}(P<0.05)$. The ORS prepared in water reached preprandial $\mathrm{pH}$ values within 1 to $2 \mathrm{~h}$, except for ORS-2B (ORS-2 contained swelling agents that retarded abomasal passage).

\section{Osmolality}

The mean preprandial osmolality of the abomasal fluid was $338 \pm 41 \mathrm{mOsm} / \mathrm{kg}(\mathrm{n}=58)$. Changes in the osmolality after feeding were dependent on the osmolality of the ORS: hypertonic ORS (MR-ORS mixtures) caused an increase, whereas water-ORS mixtures and MR did not significantly affect the abomasal osmolality (Table 3).

\section{Milk Clotting In Vitro}

In vitro, whole cow's milk reached higher values of viscosity after addition of chymosin than MR (47 vs. $20 \mathrm{mPa} \cdot \mathrm{s})$. Two of the 4 tested MR-ORS mixtures (ORS-2A and ORS-4A) failed to clot (Figure 3A): after addition of chymosin, no increase in viscosity was detected within $60 \mathrm{~min}$ (because of the swelling ingredients, ORS-2A had a higher original viscosity than $\mathrm{MR}$ or other ORS). After acidification at $\mathrm{pH} \sim 5.5$ and addition of the enzyme, milk clotting was measured in every case via an increase in viscosity (Figure 3B). Also, acidification to $\mathrm{pH} 4.7$ without chymosin caused milk clotting in every trial (data not shown).

\section{Milk Clotting In Vivo}

All samples of abomasal fluid collected after feeding MR or MR-ORS mixtures were visually clotted. Caseinomacropeptide could be identified in every sample 
A

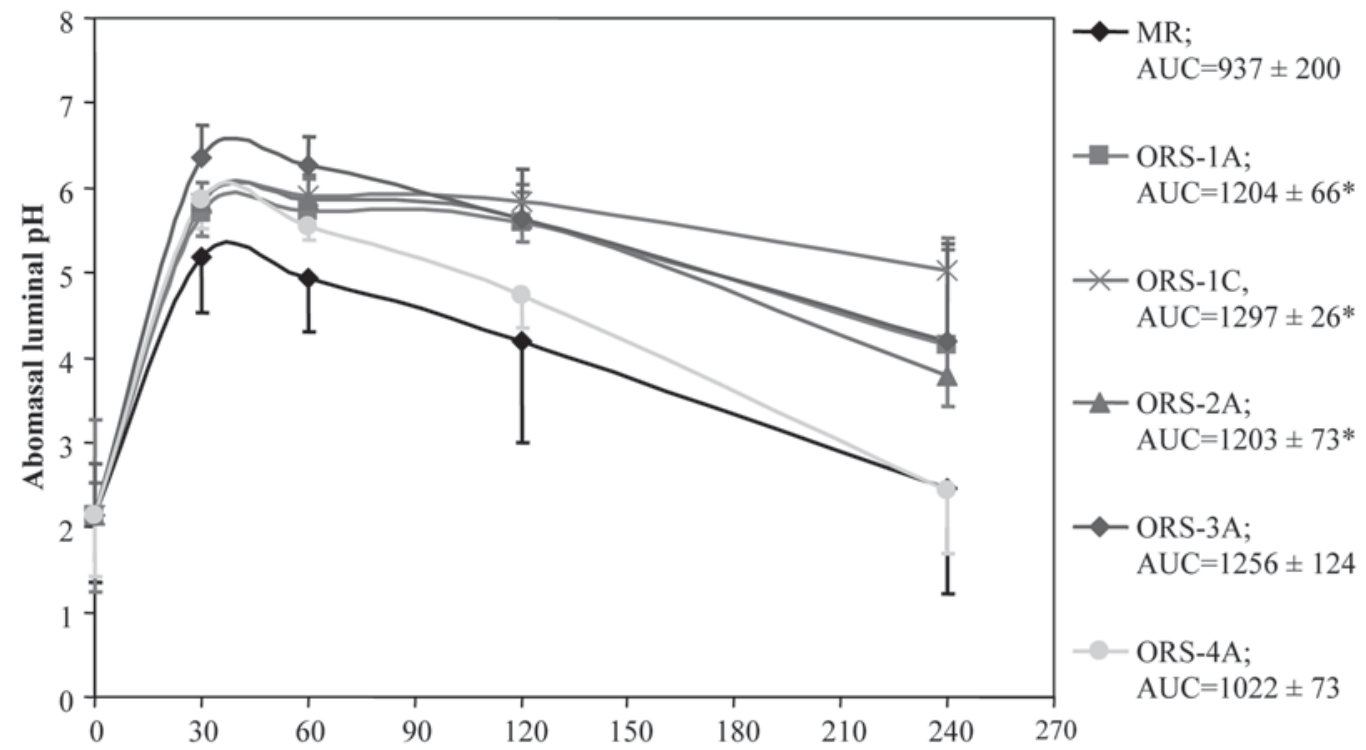

B

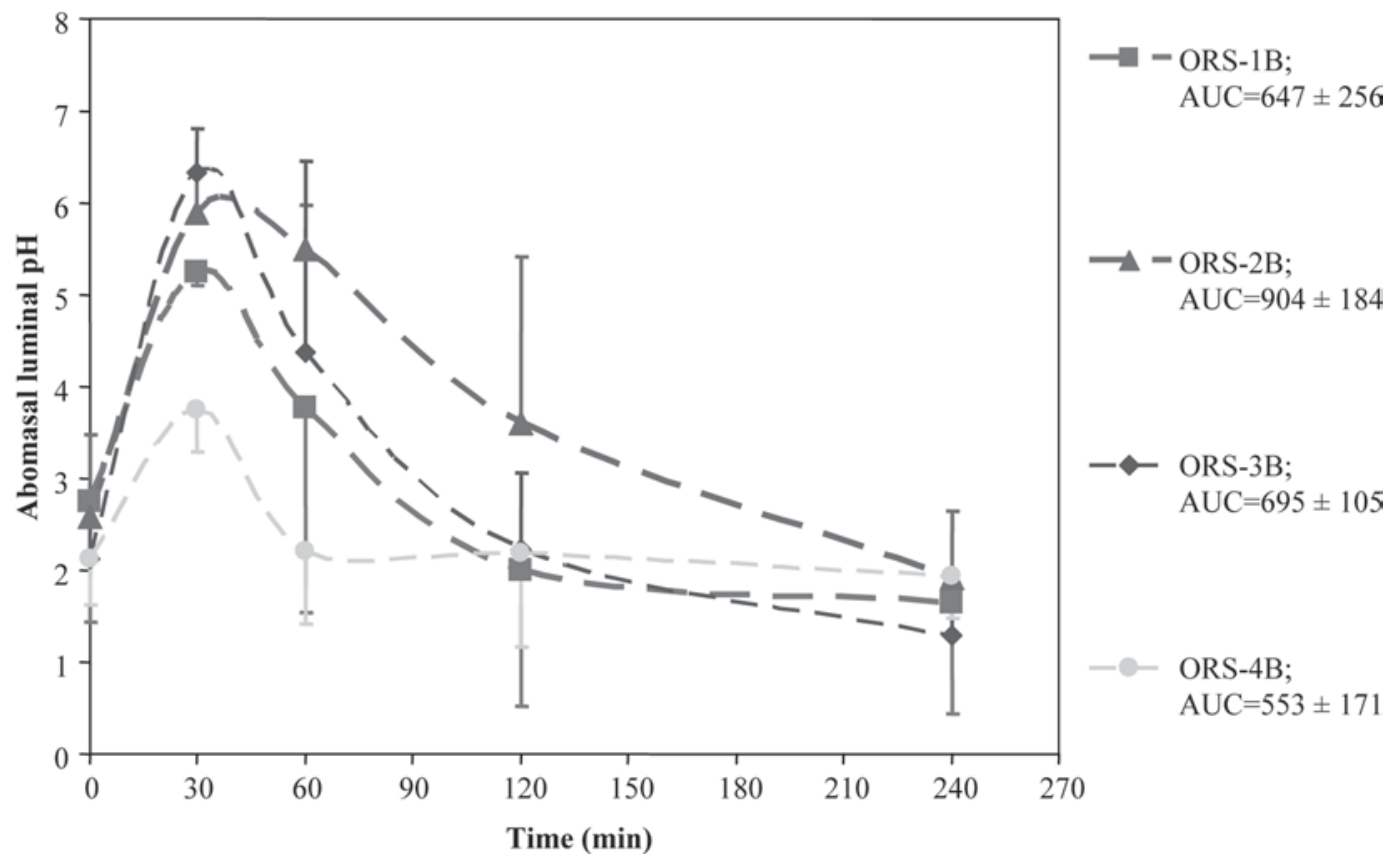

Figure 1. Abomasal $\mathrm{pH}$ after feeding of milk replacer (MR) and oral rehydration solutions (ORS). A) Mean abomasal luminal pH values and standard deviation before and $0.5,1,2$, and $4 \mathrm{~h}$ after feeding of MR or MR-ORS mixtures, respectively. Areas under curve (AUC) of the different $\mathrm{pH}$-time curves are given in the legend (arithmetic mean \pm standard deviation). The AUC values of ORS-1A, ORS-1C, and ORS-2A differed significantly from MR-AUC $\left({ }^{*} P<0.05\right)$. B) Abomasal luminal $\mathrm{pH}$ values before and $0.5,1,2$, and $4 \mathrm{~h}$ after feeding of water-ORS mixtures. With the exception of ORS-2B, all AUC values after feeding of water-ORS mixtures differed significantly from the AUC of the same ORS prepared in MR $(P<0.05)$.

of abomasal fluid after feeding of MR-ORS mixtures (Table 4), although MR and MR-ORS mixtures did not contain any CMP per se (data not shown); CMP could not be detected in $4 \mathrm{MR}$-fed samples. Comparison of CMP peak AUC after feeding of either MR or MR-ORS mixtures did not acquire any statistically significant difference.

\section{Acid-Base Status in Blood}

Two hours after feeding of ORS with $\left[\mathrm{SID}_{3}\right]$ values $\geq 92 \mathrm{mmol} / \mathrm{L}$, a statistically significant increase of serum $\left[\mathrm{SID}_{3}\right]$ was detected (Table 5). Every feeding regimen caused a slight decrease in serum $\left[\mathrm{A}_{\text {tot }}\right] 2 \mathrm{~h}$ after feeding (mean preprandial value: $18.4 \pm 0.86 \mathrm{mmol} / \mathrm{L}$, mean 
Table 3. Abomasal osmolality (means $\pm \mathrm{SD}$ )

\begin{tabular}{|c|c|c|c|c|c|}
\hline Feeding regimen ${ }^{1}$ & \multicolumn{5}{|c|}{ Abomasal osmolality (mOsm/kg) } \\
\hline MR & $341 \pm 82$ & $372 \pm 58$ & $405 \pm 117$ & $391 \pm 53$ & $339 \pm 51$ \\
\hline ORS-1B & $387 \pm 60$ & $319 \pm 68$ & $352 \pm 58$ & $334 \pm 73^{*}$ & $318 \pm 80$ \\
\hline ORS-1C & $330 \pm 70$ & $749 \pm 170^{*}$ & $724 \pm 69^{*}$ & $701 \pm 78^{*}$ & $564 \pm 89^{*}$ \\
\hline ORS-2A & $305 \pm 26$ & $619 \pm 54^{*}$ & $663 \pm 84^{*}$ & $647 \pm 94^{*}$ & $496 \pm 104^{*}$ \\
\hline ORS-4A & $301 \pm 17$ & $489 \pm 36^{*}$ & $465 \pm 46^{*}$ & $448 \pm 34^{*}$ & $324 \pm 39$ \\
\hline ORS-4B & $296 \pm 47$ & $297 \pm 25$ & $295 \pm 34$ & $302 \pm 29$ & $267 \pm 36$ \\
\hline
\end{tabular}

${ }^{1} \mathrm{MR}=$ milk replacer; ORS $=$ oral rehydration solution.

$* P<0.05$ compared with abomasal osmolality before feeding.

postprandial value: $17.9 \pm 0.69 \mathrm{mmol} / \mathrm{L})$. Venous $\mathrm{pH}$ values and $\mathrm{pCO}_{2}$ levels were not affected by the different feeding regimens (Table 6).

\section{Change in Plasma Volume}

All feeding regimens increased the plasma volume 120 min after administration (Figure 4); however, after 240 min, only plasma volumes of groups fed MR and MR-ORS mixtures were still increased, whereas plasma volumes of groups fed water-ORS mixtures were back to baseline. The MR-ORS mixtures were most effective in increasing plasma volume at the 2 determined time points, reaching statistical significance compared with MR or water-ORS mixtures $240 \mathrm{~min}$ after feeding $(P$ $<0.05)$.

\section{DISCUSSION}

Constable et al. (2005a) observed that feeding of MR causes a more pronounced abomasal $\mathrm{pH}$ increase than feeding of cow's milk. Relating the present data to the data of Reinhold et al. (2006)-maximum $\mathrm{pH}$ after cow's milk-feeding $=4.7 \pm 0.41$, AUC $=898 \pm$

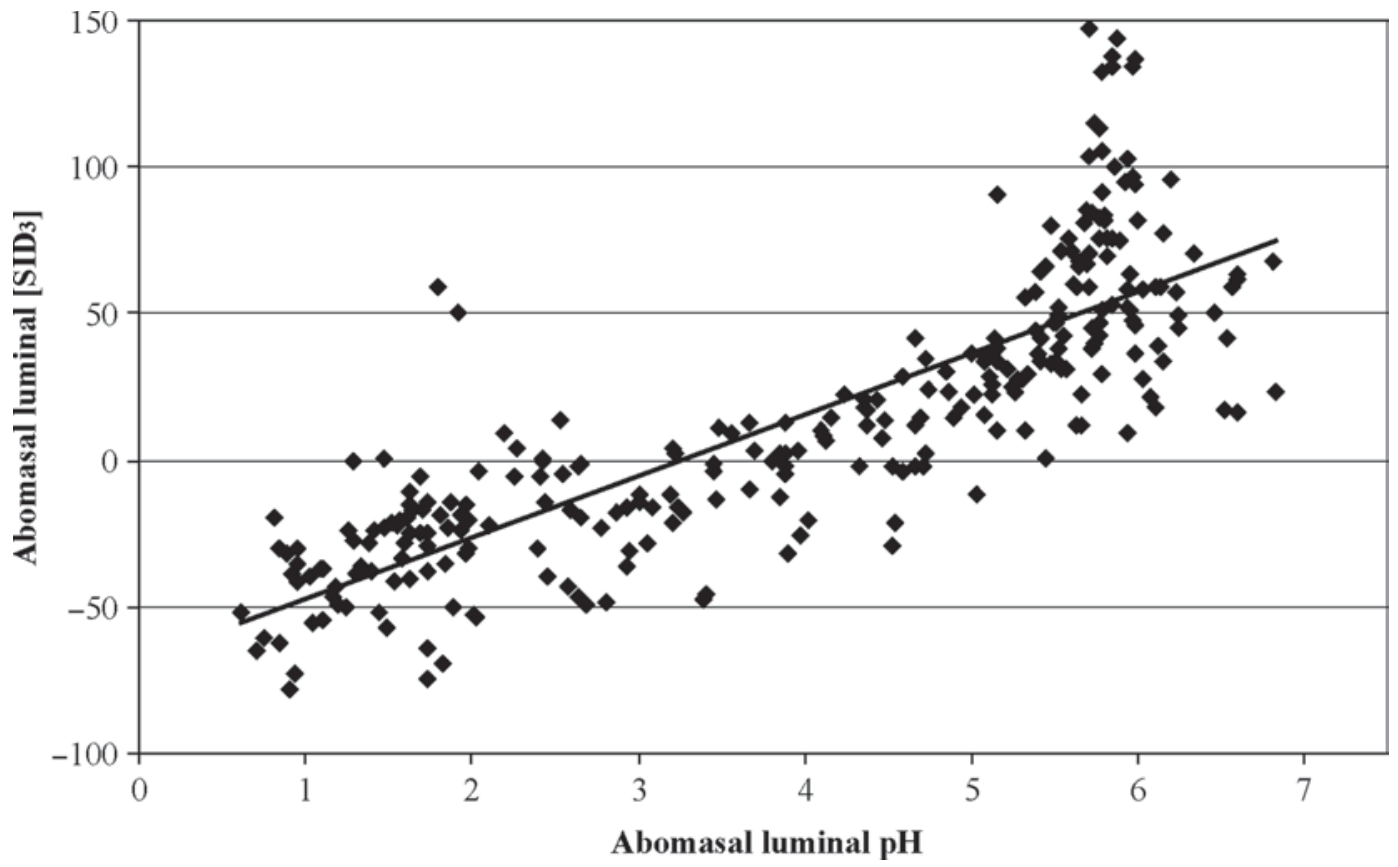

Figure 2. Correlation between strong ion difference $\left(\left[\mathrm{SID}_{3}\right]=\left[\mathrm{Na}^{+}\right]+\left[\mathrm{K}^{+}\right]-\left[\mathrm{Cl}^{-}\right]\right)$and $\mathrm{pH}$ in the abomasal fluid. Scatter plot of the relationship between $\mathrm{SID}_{3}$ and $\mathrm{pH}$ in the abomasal ingesta samples: $\mathrm{SID}_{3}$ values and $\mathrm{pH}$ were positively correlated $\left(\mathrm{r}_{\mathrm{s}}=0.824\right)$. Solid line $=$ line of regression. 
A

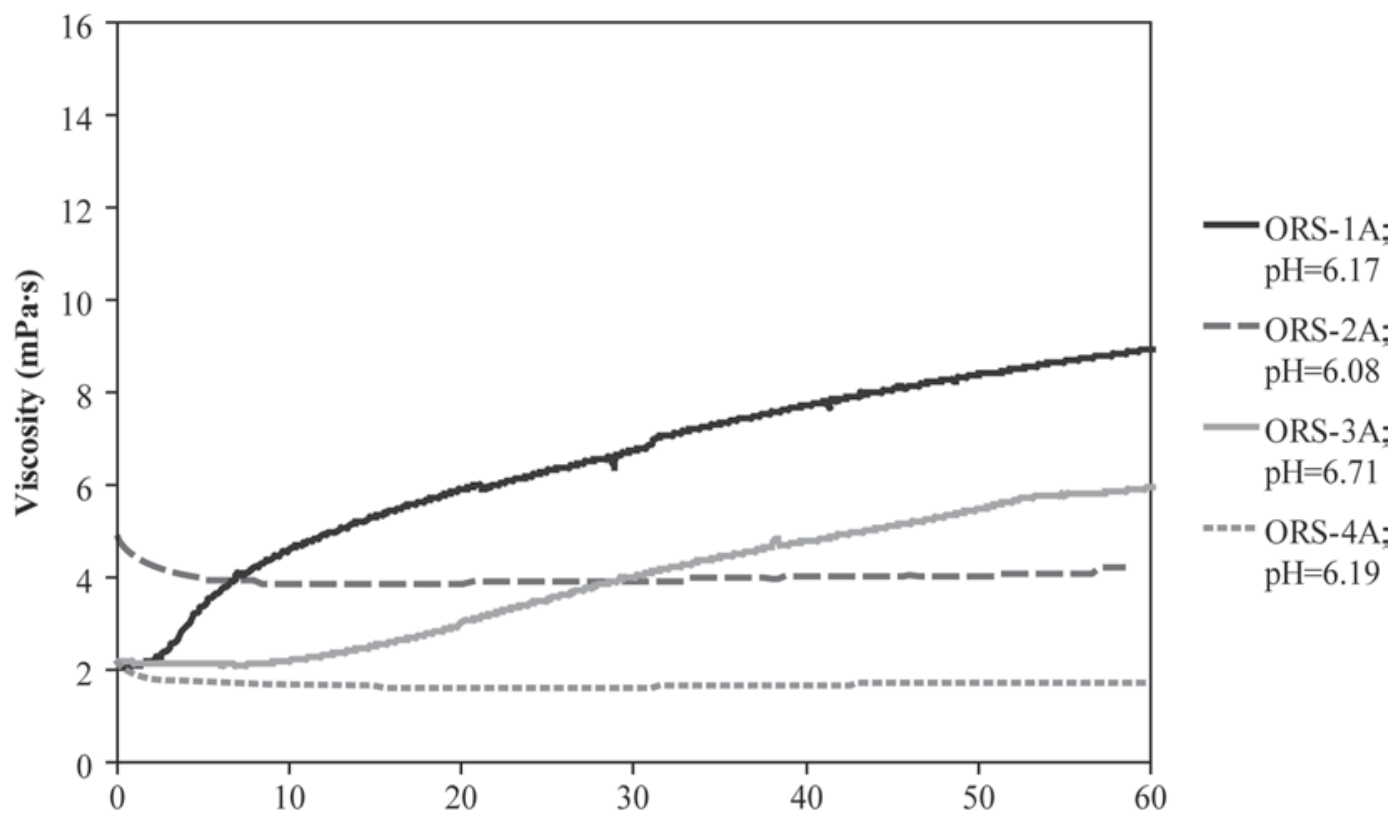

B

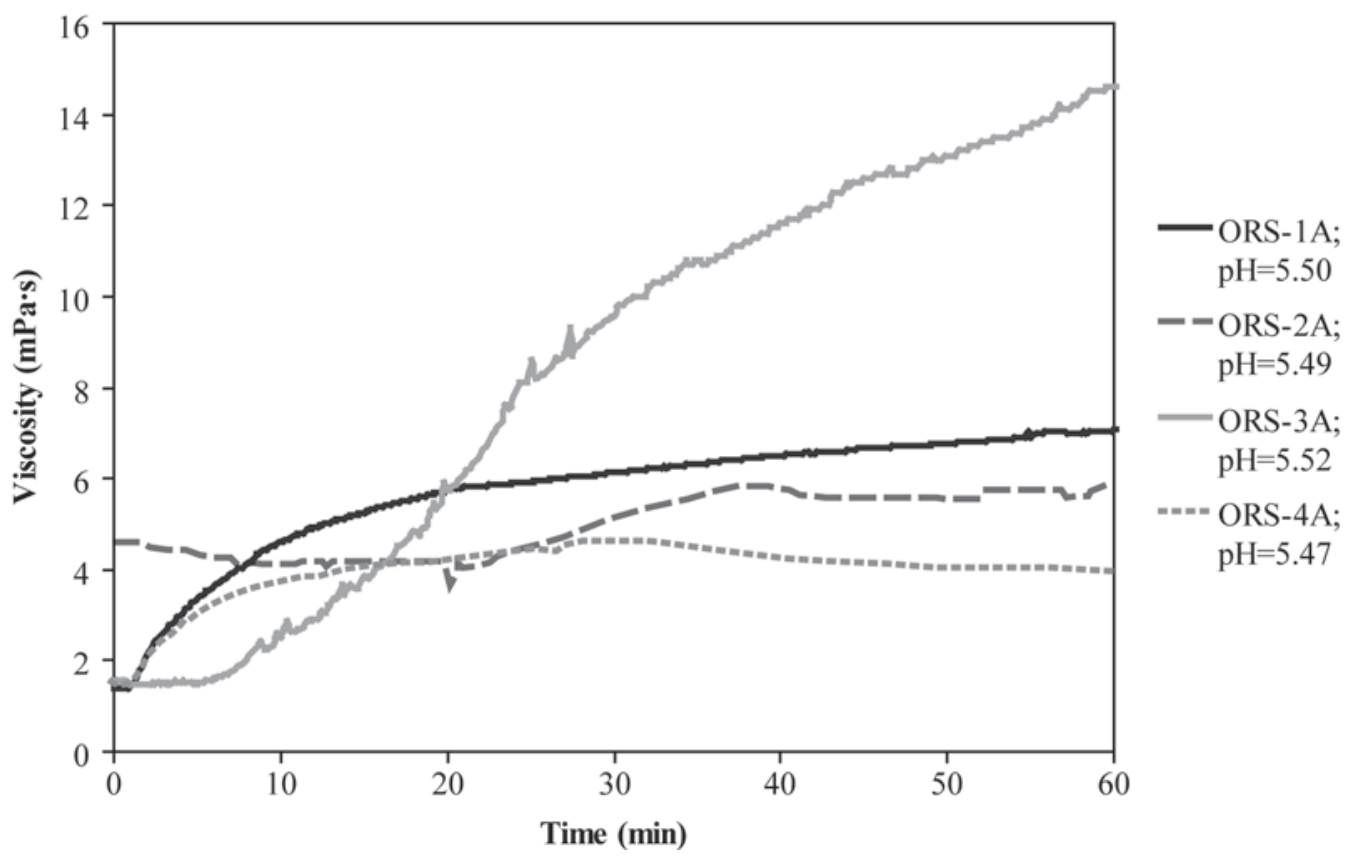

Figure 3. Milk clotting in vitro at original and acidified pH. A) Dynamic viscosity (one value every $10 \mathrm{~s}$ ) in different milk replacer-oral rehydration solution (MR-ORS) at original $\mathrm{pH}$ after adding chymosin to the solutions. B) Dynamic viscosity in different MR-ORS mixtures at acidified $\mathrm{pH}(\sim 5.5)$ after adding chymosin to the solutions.

87-we can confirm this observation. Constable et al. (2005a) hypothesized that the slightly lower abomasal $\mathrm{pH}$ in calves suckling cow's milk was probably due to clotting-associated extrusion of low $\mathrm{pH}$ whey. However, in contrast to the study of Constable et al. (2005a), the MR utilized in the present study coagulated even after addition of chymosin; hence, absent milk clotting could not explain the higher abomasal $\mathrm{pH}$ values after administration of MR. Nor could the higher osmolality of the MR and the consequently slower abomasal emptying be a reason for a higher abomasal $\mathrm{pH}$, because the administered MR $(287 \mathrm{mOsm} / \mathrm{kg})$ had almost the same 
Table 4. Area under the curve (AUC) of caseinomacropeptide (CMP) peaks in samples of abomasal fluid 30 min after feeding of milk replacer (MR) and MR-oral rehydration solution (ORS) mixtures

\begin{tabular}{llc}
\hline Feeding regimen & $\mathrm{n}$ & $\mathrm{AUC}^{1}$ \\
\hline MR & $6(10)^{2}$ & $294,955 \pm 362,455$ \\
ORS-1A & 8 & $601,257 \pm 492,178$ \\
ORS-1C & 5 & $734,510 \pm 383,110$ \\
ORS-2A & 5 & $197,657 \pm 97,245$ \\
ORS-3A & 5 & $313,259 \pm 181,974$ \\
ORS-4A & 5 & $2,360,500 \pm 1,718,060$ \\
\hline
\end{tabular}

${ }^{1}$ Comparison of CMP peak AUC of the different feeding regimens did not acquire any statistically significant difference $(P>0.05)$.

${ }^{2}$ In 4 samples of abomasal fluid, no CMP was detectable.

osmolality as cow's milk (278 mOsm $/ \mathrm{kg})$. Abomasal $\mathrm{pH}$ is also dependent on the buffering characteristics of the feeding solution. However, in the study of Constable et al. (2005a), the titration curves of cow's milk and all-milk-protein MR were similar; hence, the buffering characteristics cannot explain the different abomasal $\mathrm{pH}$-time courses. We hypothesize that it is rather the higher $\left[\mathrm{SID}_{3}\right]$ value of $\mathrm{MR}(42 \mathrm{mmol} / \mathrm{L})$ compared with that of milk (31 mmol/L; Kolb, 1989) that is the reason for higher $\mathrm{pH}$ values after an MR meal. Correspondingly, there was a correlation between the AUC of the $\mathrm{pH}$-time curve and the $\left[\mathrm{SID}_{3}\right]$ of the administered feeding formulations. In accordance with the data of Reinhold et al. (2006), no influence of the specific ORS buffer ion on abomasal pH was observed; however, abomasal $\mathrm{pH}$ correlated with the $\left[\mathrm{SID}_{3}\right]$ values in abomasal ingesta. This emphasizes the importance of SID for the $\mathrm{pH}$ adjustment in the abomasal fluid.

To estimate the abomasal emptying rate, the $\mathrm{pH}$ return time is a useful research method (Constable et al., 2006). The reduced $\mathrm{pH}$ return time observed in the present study after feeding water-ORS mixtures may be due to lower $\left[\mathrm{SID}_{3}\right]$ values, lower osmolality, less energy content, and the absence of milk clotting. However, the faster abomasal passage of water-based ORS implies that efficacious electrolytes reach the gut more quickly. Nouri and Constable (2006) observed that low-glucosecontaining ORS provides a fast rate of abomasal emptying and plasma volume expansion; hence, an earlier time point than our 120-min time point may have been useful to confirm a faster plasma expansion after feeding water-ORS mixtures. However, the results after feeding MR-ORS mixtures indicate that feeding these solutions produces a greater and sustained increase in plasma volume, which might be beneficial for treating dehydration in diarrheic calves.

Clotting of casein is thought to be responsible for improved digestibility, greater daily gains, and improved calf health. There is evidence that the types of protein sources, the manufacturing methods, and the inclusion of other less-digestible sources of nutrients in milk replacer may be the components hindering the growth and health of calves (Longenbach and Heinrichs, 1998). In the study of Heath et al. (1989), diarrheic calves that received cow's milk and an ORS containing $\mathrm{HCO}_{3}{ }^{-}$gained less weight than calves receiving milk and ORS without $\mathrm{HCO}_{3}^{-}$. These findings lead to the assumption that alkaline ORS may inhibit abomasal milk clotting and, hence, interfere with digestion as abomasal curd formation regulates the flow of fat and protein into the duodenum (Petit et al., 1987). The abomasal clotting of milk is a result of the function of chymosin and the gastric secretion of hydrochloric acid. Chymosin cleaves $\kappa$-casein into para- $\kappa$-casein and CMP, which is responsible for the solubility of the caseins in milk serum. Reports concerning the optimum

Table 5. Serum strong ion difference $\left(\left[\mathrm{SID}_{3}\right]=\left[\mathrm{Na}^{+}\right]+\left[\mathrm{K}^{+}\right]-\left[\mathrm{Cl}^{-}\right]\right)$changes after feeding of different feeding formulations

\begin{tabular}{llll}
\hline & \multicolumn{3}{c}{ Serum $\left[\mathrm{SID}_{3}\right](\mathrm{mmol} / \mathrm{L})$} \\
\cline { 2 - 4 } Feeding regimen $^{1}$ & Before feeding & After $120 \mathrm{~min}$ & After $240 \min$ \\
\hline $\mathrm{MR}$ & $46.0 \pm 1.63^{\mathrm{a}}$ & $45.6 \pm 1.67^{\mathrm{a}}$ & $44.8 \pm 1.65^{\mathrm{b}}$ \\
ORS-1A $^{2}$ & $46.8 \pm 1.73^{\mathrm{a}}$ & $47.8 \pm 1.59^{\mathrm{b}}$ & $47.3 \pm 1.95^{\mathrm{ab}}$ \\
ORS-1B $_{\text {ORS-1C }}$ & $46.2 \pm 2.68^{\mathrm{ab}}$ & $46.1 \pm 2.07^{\mathrm{a}}$ & $45.0 \pm 1.43^{\mathrm{b}}$ \\
ORS-2A $^{2}$ & $46.3 \pm 2.01^{\mathrm{a}}$ & $48.7 \pm 1.91^{\mathrm{b}}$ & $48.1 \pm 2.34^{\mathrm{ab}}$ \\
ORS-2B $_{\text {ORS-3A }}$ & $47.8 \pm 2.46^{\mathrm{a}}$ & $48.9 \pm 2.29^{\mathrm{b}}$ & $48.5 \pm 2.16^{\mathrm{ab}}$ \\
ORS-3B $_{\text {ORS-4A }}$ & $47.1 \pm 2.23^{\mathrm{a}}$ & $47.1 \pm 2.20^{\mathrm{a}}$ & $45.2 \pm 2.54^{\mathrm{b}}$ \\
ORS-4B & $44.8 \pm 1.41^{\mathrm{a}}$ & $46.6 \pm 1.54^{\mathrm{b}}$ & $45.8 \pm 0.78^{\mathrm{ab}}$ \\
\hline
\end{tabular}

${ }^{\mathrm{a}, \mathrm{b}}$ Means within a row with different superscript letters indicate statistically significant differences between the individual points in time.

${ }^{1} \mathrm{MR}=$ milk replacer (Kälbermilch UNI, Raiffeisen GmbH, Muenster, Germany); ORS = oral rehydration solutions.

${ }^{2} \mathrm{ORS}$ with $\left[\mathrm{SID}_{3}\right]$ values $\geq 92 \mathrm{mmol} / \mathrm{L}$. 


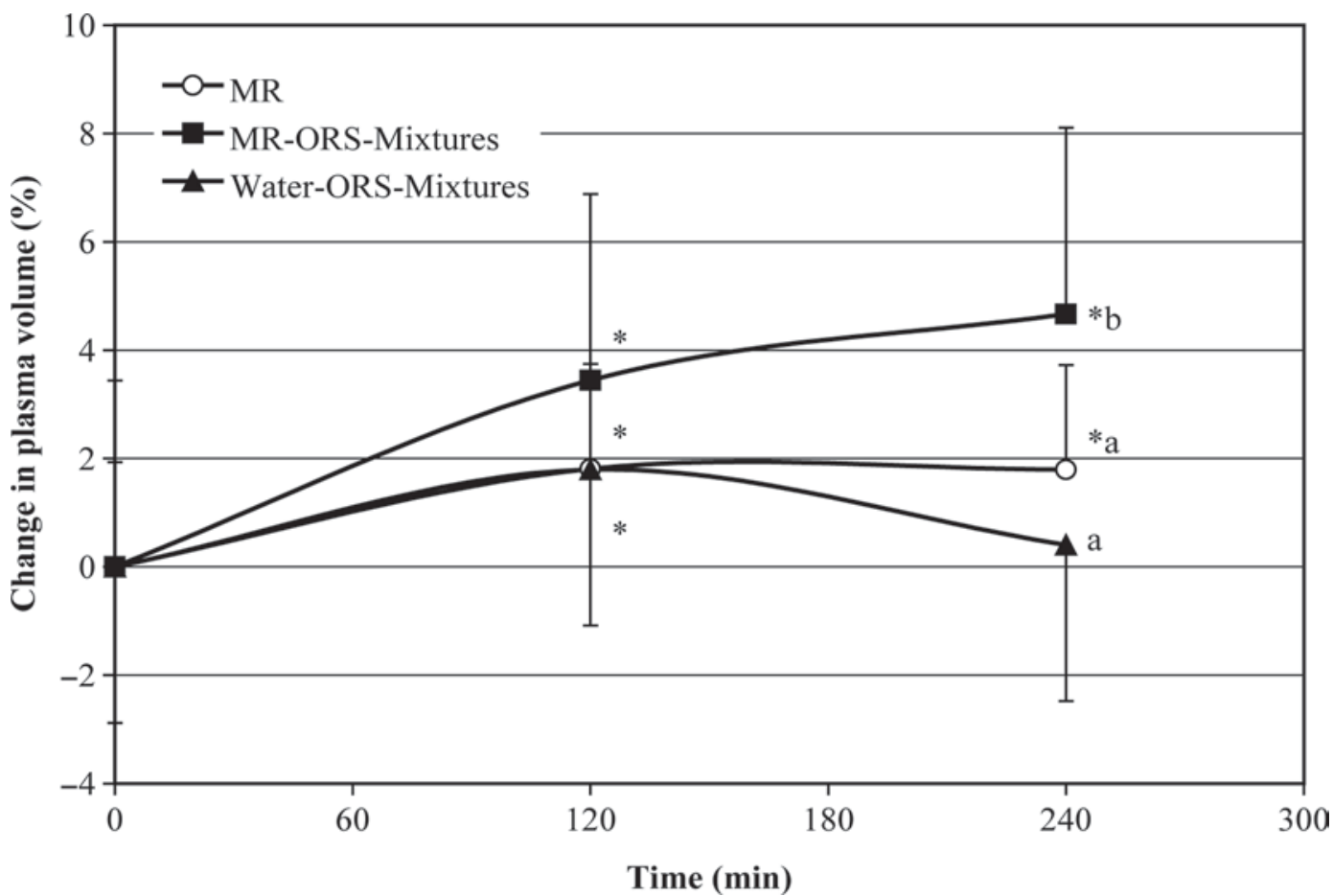

Figure 4. Change in plasma volume. Calculated change in plasma volume (arithmetic mean \pm standard deviation) after 58 feeding times in total. Asterisks $(*)$ indicate statistically significant differences from baseline. Lowercase letters indicate statistically significant differences between water-oral rehydration solution (ORS) mixtures and milk replacer $(\mathrm{MR})\left(^{\mathrm{a}}\right)$ or MR-ORS mixtures and the other 2 feeding regimens $\left({ }^{b}\right)$, respectively.

$\mathrm{pH}$ of chymosin activity differ from $\mathrm{pH} 3.5$ (Foltmann, 1969) to 5 or 5.5 (Miyoshi et al., 1976; Fox et al., 1996), whereas chymosin activity in milk is said to be maximal at $\mathrm{pH} 6$ (Dalgleish, 1992). The chymosin coagulation of milk is a 3 -stage process. Via its enzymatic action, CMP is released into the milk serum. In the second phase, casein micelles begin to aggregate and form a gel network. This stage of milk clotting is accompanied by a change in viscosity. Consecutively, the network is strengthened and the curd and the liquid whey are separated (Brückner and Senge, 2007). The acidifica- tion of milk to a $\mathrm{pH}$ of 4.7 also causes precipitation of the caseins. This $\mathrm{pH}$ value is the isoelectric point of the caseins so that the casein micelles lose stability due to charge equalization (Dalgleish, 1992).

In some in vitro studies with ORS, especially with those containing $\mathrm{HCO}_{3}^{-}$and citrate or high amounts of glucose, enzymatic clotting of milk was prevented (Naylor, 1992; Nappert and Spennick, 2003). In the present study, in vitro clotting of cow's milk reached a higher viscosity than MR, which could be explained by the heat treatment of MR milk proteins (Fox et al., 1996).

Table 6. Venous $\mathrm{pH}$ values and partial pressure of $\mathrm{CO}_{2}\left(\mathrm{pCO}_{2}, \mathrm{kPa}\right)$ after feeding different feeding formulations

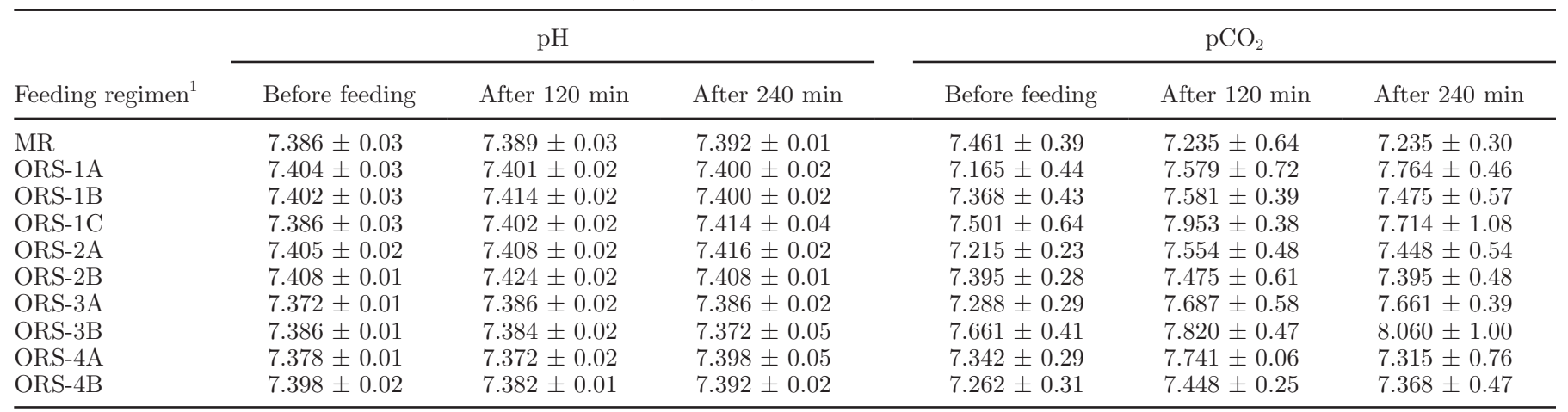

${ }^{1} \mathrm{MR}=$ milk replacer (Kälbermilch UNI, Raiffeisen GmbH, Muenster, Germany); ORS = oral rehydration solutions. 
Although the quality (viscosity) of the gel formation of clotted milk is an important objective of cheese production (Brückner and Senge, 2007), in abomasal milk clotting the degree of the curd viscosity with incorporated whey is not the determining factor, as in vivo, milk clotting is responsible for the prolonged duration of caseins in the abomasum (Petit et al., 1987).

Simulation of the conditions occurring naturally in the abomasum showed that milk clotting proceeded in every MR-ORS mixture. At original pH, ORS containing propionate and citrate failed to clot milk. Interestingly, the $\mathrm{HCO}_{3}{ }^{-}$-containing ORS did not inhibit milk clotting at the original $\mathrm{pH}$ or at $\mathrm{pH} \sim 5.5$. The results of the in vitro experiments contradict previous studies on ORS and their effects on milk clotting (Naylor, 1992; Nappert and Spennick, 2003); however, in these trials, the influence of gastric acidification was not included.

Because Miyazaki et al. (2009) showed that in vitro milk clotting is only a reference, not evidence of successful abomasal milk clotting, abomasal fluid samples were collected at several time points after feeding. All samples of abomasal ingesta were visibly clotted $30 \mathrm{~min}$ after administration of MR or MR-ORS mixtures. Caseinomacropeptide could be identified in all abomasal fluid samples after feeding of MR-ORS mixtures; hence, enzymatic milk clotting occurred in the abomasum.

After feeding of MR only, CMP could not be detected in 4 samples of abomasal fluid, but as $\mathrm{pH}$ values in these samples were $\leq 4.7$, milk clotting may have occurred simply because of the acidity or CMP were possibly cleaved into smaller peptides by the gastric proteases. According to these in vitro and in vivo results, ORS do not interfere with milk clotting in the abomasum.

In human medicine, the effects of fluid therapy on the Stewart variables were analyzed and intravenous fluid therapy was improved by these findings (Gunnerson and Kellum, 2003). A successful correction of acidosis in diarrheic calves is associated with an increase in $\left[\mathrm{SID}_{3}\right]$ in serum (Grove-White and Michell, 2001). Hence, ORS with higher SID concentrations should be more effective when treating acidemic calves. Staempfli et al. (1996) observed that an ORS with highly effective $\left[\mathrm{SID}_{3}\right]$ values $(88.3 \pm 4.7 \mathrm{mmol} / \mathrm{L})$ can successfully correct metabolic acidosis in diarrheic calves. Constable et al. (2005b) calculated $\left[\mathrm{SID}_{3}\right]$ for commercial ORS utilized in 5 clinical trials. In these studies, ORS with high $\left[\mathrm{SID}_{3}\right](79-93 \mathrm{mmol} / \mathrm{L})$ were more effective in correcting dehydration and metabolic acidosis than ORS with lower $\left[\mathrm{SID}_{3}\right]$ values. In the present study, ORS with $\left[\mathrm{SID}_{3}\right] \geq 92 \mathrm{mmol} / \mathrm{L}$ caused an increase of serum $\left[\mathrm{SID}_{3}\right]$. Moreover, a slight decrease of serum $\left[\mathrm{A}_{\text {tot }}\right]$ was observed after every feeding, which was probably due to the general dilution of blood by fluid absorption. The observed changes in serum $\left[\mathrm{SID}_{3}\right]$ and serum $\left[\mathrm{A}_{\text {tot }}\right]$ are able to cause an alkaline response in the organism (Constable, 1999), an effect that could potentially also reduce acidosis in calves suffering from diarrhea.

The principal limitation of our study is that calves did not suffer from diarrhea or acidosis, which might have influenced the results and should, therefore, be tested in future experiments. Moreover, only 3 calves were examined and calves were 14 to $38 \mathrm{~d}$ of age and therefore slightly older than typical ORS recipients.

\section{CONCLUSIONS}

The strong ion difference theory is a useful tool when formulating ORS. In this study, ORS with $\left[\mathrm{SID}_{3}\right] \geq 92$ $\mathrm{mmol} / \mathrm{L}$ increased serum $\left[\mathrm{SID}_{3}\right]$, suggesting that effective ORS should contain high $\left[\mathrm{SID}_{3}\right]$ values. Although such ORS also increase abomasal pH, they do not interfere with milk clotting in the abomasum; hence, feeding of MR or milk in combination with ORS is possible. Administration of these MR-ORS mixtures causes a more pronounced expansion of plasma volume, which is beneficial for the correction of dehydration in diarrheic calves.

\section{ACKNOWLEDGMENTS}

This project was supported by Bayer Health Care. The authors thank Esther Maria Antao (Institute of Microbiology and Epizootics, Freie Universitaet Berlin, Berlin, Germany) for the linguistic revision of the manuscript, Sabine Reinhold (Department of Veterinary Physiology, Freie Universitaet Berlin, 14163 Berlin, Germany) for establishing the surgical procedures, and the Department of Animal Reproduction, Freie Universitaet Berlin, for caring for the animals.

\section{REFERENCES}

Brückner, M., and B. Senge. 2007. Casein and structural changes during the rennet-induced coagulation of bulk raw milk and milk from infected udder quarters of cows. Milchwissenschaft 62:245249.

Constable, P. D. 1997. A simplified strong ion model for acid-base equilibria: Application to horse plasma. J. Appl. Physiol. 83:297311.

Constable, P. D. 1999. Clinical assessment of acid-base status: Strong ion difference theory. In Fluid and Electrolyte Therapy. Vet. Clin. North Am. Food Anim. Pract. 15:447-471.

Constable, P. D. 2002. Calculation of variables describing plasma nonvolatile weak acids for use in the strong ion approach to acidbase balance in cattle. Am. J. Vet. Res. 63:482-490.

Constable, P. D., A. F. Ahmed, and N. A. Misk. 2005a. Effect of suckling cow's milk or milk replacer on abomasal luminal $\mathrm{pH}$ in dairy calves. J. Vet. Intern. Med. 19:97-102.

Constable, P. D., H. R. Staempfli, H. Navetat, J. Berchtold, and F. Schelcher. 2005b. Use of a quantitative strong ion approach to determine the mechanism for acid-base abnormalities in sick calves with or without diarrhea. J. Vet. Intern. Med. 19:581-589.

Constable, P. D., T. Wittek, A. F. Ahmed, T. S. Marshall, I. Sen, and M. Nouri. 2006. Abomasal pH and emptying rate in the calf and 
dairy cow and the effect of commonly administered therapeutic agents. Pages 54-68 in Proc.World Buiatrics Congr., Nice, France. World Association for Buiatrics, Nice, France.

Dalgleish, D. G. 1992. The enzymatic coagulation of milk. Pages 579619 in Advanced Dairy Chemistry. Volume 1: Proteins. P. F. Fox, ed. Elsevier Applied Science, London, UK.

FASS. 1999. Guide for the Care and Use of Agricultural Animals in Agricultural Research and Teaching. 1st rev. ed. FASS, Savoy, IL.

Foltmann, B. 1969. Prochymosin and chymosin (prorennin and rennin). Biochem. J. 115:3-4.

Fox, P. F., T. P. O'Connor, and P. L. H. McSweeney. 1996. Cheese: Physical, biochemical and nutritional aspects. Adv. Food Nutr. Res. 39:163-193.

Garthwaite, B. D., J. K. Drackley, G. C. McCoy, and E. H. Jaster. 1994. Whole milk and oral rehydration solution for calves with diarrhea of spontaneous origin. J. Dairy Sci. 77:835-843.

Grove-White, D. H., and A. R. Michell. 2001. Comparison of the measurement of total carbon dioxide and strong ion difference for the evaluation of metabolic acidosis in diarrhoeic calves. Vet. Rec. 148:365-370.

Gunnerson, K. J., and J. A. Kellum. 2003. Acid-base and electrolyte analysis in critically ill patients: Are we ready for the new millennium? Curr. Opin. Crit. Care 9:468-473.

Hartmann, H., J. Berchtold, and W. Hofmann. 1997. Pathophysiological aspects of acidosis in diarrhoeic calves. Tierarztl. Umsch. 52:568 574 .

Heath, S. E., J. M. Naylor, B. L. Guedo, L. Petrie, C. G. Rousseaux, and O. M. Radostits. 1989. The effects of feeding milk to diarrheic calves supplemented with oral electrolytes. Can. J. Vet. Res. $53: 477-485$.

Kolb, E. 1989. Lehrbuch der Physiologie der Haustiere. Gustav Fischer Verlag, Jena, Germany.

Longenbach, J. I., and A. J. Heinrichs. 1998. A review of the importance and physiological role of curd formation in the abomasum of young calves. Anim. Feed Sci. Technol. 73:85-97.

Lorenz, I., A. Gentile, and W. Klee. 2005. Investigations of D-lactate metabolism and the clinical signs of D-lactataemia in calves. Vet. Rec. 156:412-415.

Minikiewicz, P., C. J. Slangen, F. M. Lagerwerf, J. Haverkamp, H. S. Rollema, and S. Visser. 1996. Reversed-phase high-performance liquid chromatographic separation of bovine kappa-casein macropeptide and characterization of isolated fractions. J. Chromatogr. A 743:123-135.

Miyazaki, T., M. Miyazaki, J. Yasuda, and K. Okada. 2009. Ultrasonographic imaging of abomasal curd in preruminant calves. Vet. J. 179:109-116.

Miyoshi, M., C. H. Yoon, F. Ibuki, and M. Kanamori. 1976. Characterization of rennin action on $\kappa$-casein using cm-cellulose. Agric. Biol. Chem. 40:347-352.

Nappert, G., and H. Spennick. 2003. Effects of neonatal calf oral rehydration therapy solutions on milk clotting time. Cattle Pract. 11:285-288.

Naylor, J. M. 1992. Effects of electrolyte solutions for oral administration on clotting of milk. J. Am. Vet. Med. Assoc. 201:1026-1029.

Nouri, M., and P. D. Constable. 2006. Comparison of two oral electrolyte solutions and route of administration on the abomasal emptying rate of Holstein-Friesian calves. J. Vet. Intern. Med. 20:620-626.

Petit, H., M. Ivan, and G. J. Brisson. 1987. Duodenal flow of digesta in preruminant calves fed clotting or nonclotting milk replacer. J. Dairy Sci. 70:2570-2576.

Reinhold, S., B.-W. Hertsch, S. Höppner, W. Heuwieser, and H. Hartmann. 2006. Effect of milk and oral electrolyte solutions with and without bicarbonate on abomasal luminal $\mathrm{pH}$ and systemic acid-base status in calves. Tierarztliche Praxis Ausgabe Grosstiere Nutztiere 34:368-376.

Staempfli, H. R., J. H. Pringle, J. H. Lumsden, O. Oliver, B. Kilmer, and J. D. Baird. 1996. Experimental evaluation of a novel oral electrolyte solution in the treatment of natural occuring neonatal calf diarrhoea. Br. Cattle Vet. Assoc., Edinburgh, UK.

Stewart, P. A. 1981. How to understand acid-base. Elsevier North Holland Inc., New York, NY.

US Department of Agriculture. 2007. Dairy 2007 Part II: Changes in the U.S. Dairy Cattle Industry, 1991-2007. Veterinary Services. National Animal Health Monitoring System. Animal and Plant Health Inspection Service, Fort Collins, CO.

Weigler, B. J., D. W. Hird, W. M. Sischo, J. C. Holmes, C. Danayeelmi, C. W. Palmer, and W. W. Utterback. 1990. Veterinary and nonveterinary costs of disease in 29 California dairies participating in the National Animal Health Monitoring System from 1988 to 1989. J. Am. Vet. Med. Assoc. 196:1945-1949. 